\title{
The epigenetic clock as a predictor of disease and mortality risk: a systematic review and meta-analysis
}

\author{
Peter D. Fransquet ${ }^{1,2 \dagger}$, Jo Wrigglesworth ${ }^{1 \dagger}$, Robyn L. Woods', Michael E. Ernst ${ }^{4,5}$ and Joanne Ryan ${ }^{1,2,3^{*}}$
}

\begin{abstract}
Background: Ageing is one of the principal risk factors for many chronic diseases. However, there is considerable between-person variation in the rate of ageing and individual differences in their susceptibility to disease and death. Epigenetic mechanisms may play a role in human ageing, and DNA methylation age biomarkers may be good predictors of age-related diseases and mortality risk. The aims of this systematic review were to identify and synthesise the evidence for an association between peripherally measured DNA methylation age and longevity, age-related disease, and mortality risk.

Methods: A systematic search was conducted in line with the Preferred Reporting Items for Systematic Reviews and Meta-Analyses (PRISMA) guidelines. Using relevant search terms, MEDLINE, Embase, Cochrane Central Register of Controlled Trials, and PsychINFO databases were searched to identify articles meeting the inclusion criteria. Studies were assessed for bias using Joanna Briggs Institute critical appraisal checklists. Data was extracted from studies measuring age acceleration as a predictor of age-related diseases, mortality or longevity, and the findings for similar outcomes compared. Using Review Manager 5.3 software, two meta-analyses (one per epigenetic clock) were conducted on studies measuring all-cause mortality.
\end{abstract}

Results: Twenty-three relevant articles were identified, including a total of 41,607 participants. Four studies focused on ageing and longevity, 11 on age-related disease (cancer, cardiovascular disease, and dementia), and 11 on mortality. There was some, although inconsistent, evidence for an association between increased DNA methylation age and risk of disease. Meta-analyses indicated that each 5-year increase in DNA methylation age was associated an 8 to $15 \%$ increased risk of mortality.

Conclusion: Due to the small number of studies and heterogeneity in study design and outcomes, the association between DNA methylation age and age-related disease and longevity is inconclusive. Increased epigenetic age was associated with mortality risk, but positive publication bias needs to be considered. Further research is needed to determine the extent to which DNA methylation age can be used as a clinical biomarker.

Keywords: Ageing, Age-related disease, Biological age, DNA methylation, Epigenetic clock, Longevity, Mortality, Systematic review

\footnotetext{
* Correspondence: joanne.ryan@monash.edu

Peter D. Fransquet and Jo Wrigglesworth are joint first authors.

'Department of Epidemiology and Preventive Medicine, Monash University,

ASPREE, Level 5, The Alfred Centre, 99 Commercial Road, Melbourne, Victoria

3004, Australia

${ }^{2}$ Disease Epigenetics, Murdoch Childrens Research Institute, The University of

Melbourne, Parkville, Victoria 3052, Australia

Full list of author information is available at the end of the article
}

C The Author(s). 2019 Open Access This article is distributed under the terms of the Creative Commons Attribution 4.0 International License (http://creativecommons.org/licenses/by/4.0/), which permits unrestricted use, distribution, and reproduction in any medium, provided you give appropriate credit to the original author(s) and the source, provide a link to the Creative Commons license, and indicate if changes were made. The Creative Commons Public Domain Dedication waiver (http://creativecommons.org/publicdomain/zero/1.0/) applies to the data made available in this article, unless otherwise stated. 


\section{Background}

The population is ageing $[1,2]$, and age is one of the strongest risk factors for many human diseases, such as cardiovascular, metabolic and neurological diseases, and cancer [3]. This increased burden represents a major societal, economic, and public health challenge. Individuals, however do not all age to the same extent. There is considerable between-person variation in the rate of ageing, and individual differences in their susceptibility to disease and death. The identification of individuals at greatest risk of age-related diseases and death would provide important opportunities for targeting prevention and intervention.

There is thus great interest in molecular targets as clinical biomarkers which accurately predict the risk of age-related diseases and mortality. These biomarkers, which include cellular senescence, genomic instability, telomere attrition, and mitochondrial dysfunction, appear to capture pivotal aspects of biological age [4] and have been associated with a number of age-related diseases and mortality.

It is well established that as individuals age, there is a raft of molecular changes that occur within the cells and tissues. Changes in DNA methylation patterns have been shown to occur with ageing [5] and thus may be a fundamental mechanism that drives human ageing [6]. Epigenetic biomarkers of ageing, otherwise known as the epigenetic clock, have been developed using DNA methylation measurements. Referred to specifically as 'DNA methylation age' (DNAmAge), they provide an accurate estimate of age across a range of tissues, and at different stages of life $[7,8]$, and are some of the most promising biomarkers of ageing $[9,10]$. DNAmAge has also permitted the identification of individuals who show substantial deviations from their actual chronological age, and this 'accelerated biological aging' has been associated with unhealthy behaviours [11], frailty [12], cancer [13], diabetes [14], cardiovascular diseases (CVD) [15], dementia [16], and mortality risk [17].

In the last few years, two meta-analyses of 13 studies ( $n=$ $13,089)$ and 4 studies $(n=4658)$, respectively, have been undertaken to investigate the extent to which DNAmAge in blood predicts mortality risk $[17,18]$. Both reported a significant association between increased DNAmAge and mortality risk. However, neither was undertaken as part of a systematic review, raising the possibility that the findings were not representative of all research that has been undertaken in the field. To date, there has also been no systematic review that has investigated whether DNAmAge biomarkers are predictors of age-related diseases or longevity.

The aim of this systematic review is to identify and synthesise the evidence for an association between DNAmAge measured in peripheral tissues (blood, saliva, buccal cells), and longevity, age-related disease, and mortality risk.

\section{Methods}

This systematic review protocol was registered as number CRD42018108568 on the international website for systematic reviews, PROSPERO (the International Prospective Register of Ongoing Systematic Reviews) [19]. The Preferred Reporting Items for Systematic Reviews and Meta-Analyses (PRISMA) guidelines (http://www.prismastatement.org) [20,21] were closely adhered to in the preparation of this systematic review.

\section{Inclusion criteria}

\section{Types of studies and participants}

Cross-sectional studies, prospective cohorts, and case-control studies were eligible for inclusion in this review. Studies involving humans of any age, gender, race and ethnicity, and who were recruited from either the general community or a specific patient group, were eligible for inclusion. Animal studies, in vitro, and in vivo experiments were excluded.

\section{Epigenetic clock (DNA methylation age)}

Studies were eligible for inclusion in this systematic review if they extracted DNA from peripheral biological samples (blood, saliva, buccal swabs) and measured DNA methylation.

Studies met our eligibility criteria if they assessed DNAmAge with at least one of the two most widely used and well-validated epigenetic clocks; the Horvath clock [8] and Hannum's clock [7]. The Horvath estimator is based on DNA methylation at 353 cytosine-phosphate-guanine base pairs (CpGs) [22]. The Hannum estimator is based on DNA methylation at 71 distinct CpGs.

To ascertain whether participants are biologically older or younger compared to their actual age, age acceleration (AA) is measured. This is done by determining the difference between an individual's DNAmAge and their chronological age.

There are also some more recent variations to the AA measurements. Specifically, 'intrinsic epigenetic age acceleration' (IEAA) takes into account measures of blood cell counts and adjusts for this accordingly [23]. This provides a measure of AA independent of changes in blood cell composition, which can occur with age [24] or in response to immune system functions [23].

Another measure is 'extrinsic epigenetic age acceleration' (EEAA) [18], which incorporates the changes in cell composition by using a weighted average of age-associated cell counts. It thus provides a measure of AA that incorporates changes in age-related cell composition.

The eligible estimates of DNAmAge acceleration that were included in this review were thus: 
1. Age acceleration calculated with Horvath's clock (AAH)

2. Age acceleration calculated with Hannum's clock (AAHa)

3. Intrinsic epigenetic age acceleration calculated with Horvath's clock (IEAAH)

4. Intrinsic epigenetic age acceleration calculated with Hannum's clock (IEAAHa)

5. Extrinsic epigenetic age acceleration calculated with Hannum's clock (EEAA)

Studies using publicly available DNA methylation data were also included if they fit the other inclusion criteria.

\section{Outcome measures and timing}

This systematic review included studies focusing on age-related diseases (of any type), mortality, and longevity. Studies measuring associations with age-related disease, either tracked disease incidence in individuals initially free of the disease (and when DNAmAge was assessed), or compared DNAmAge between groups based on the presence or absence of disease (case-control study). Studies were excluded if they only measured the risk factors for age-related diseases (i.e. hypertension, hypercholesterolemia, obesity). We also included studies that investigated all-cause or cause-specific mortality and any studies which specifically looked at longevity.

\section{Search strategy}

A systematic search was conducted to identify relevant articles published through 2 September 2018, using the following databases: MEDLINE, Embase, Cochrane Central Register of Controlled Trials, and PsychINFO. Search terms included [epigenetic clock or epigenetic ag* or methylation ag* or (biological ag* and methyl*)] and [blood or serum or plasma or peripheral or leukocyte or $\mathrm{PBMC}^{*}$ or mononuclear or buccal or saliva] and [longevity or mortality or death* or disease* or condition*]. A grey literature and Google Scholar search were also performed. Additional studies were identified by searching the reference list of the review articles identified from the database search, as well as those of the included studies. Studies that were published in either English or French were eligible for inclusion.

\section{Synthesis of the data}

After removal of duplicate articles, the title and abstracts were screened independently by two authors (JR and JW) to assess initial eligibility. The full text of any seemingly eligible article was then obtained, and suitability for inclusion in the systematic review was again assessed. Data was extracted independently by three authors (JR, $\mathrm{JW}$, and PF) on a form developed specifically for this review and included information about the study design, location, and sample characteristics; the biological sample that was available, how DNA methylation was measured, and the calculator used to determine DNAmAge and AA; as well as the main findings from the study and any adjustment that was used in the analysis. Any discrepancies were resolved through discussion or consultation with a third author.

After having assessed the clinical and methodical heterogeneity, studies were grouped according to common outcome assessments. Where studies were considered clinically homogenous, and measured mortality outcomes, a meta-analysis was performed. For outcomes which were clinically too heterogenous, results are summarised quantitatively in tables and via a narrative synthesis, grouped according to types of outcomes.

Estimates of effect size were reported as correlations or beta values and standard errors from a linear regression for longevity outcomes, as odds ratios and 95\% confidence intervals $(95 \% \mathrm{CI})$ for dichotomous outcomes, or as hazard ratios (HR) and 95\% CI for time-to-event (disease or mortality).

\section{Methodological quality assessment}

The papers that were included in the systematic review were all assessed for methodological quality using the Joanna Briggs Institute (JBI) Critical Appraisal Checklist for Cohort Study or Case-Study, as deemed appropriate [25]. For each study, the criteria listed on the checklist were rated as having a low, unclear, or high risk of bias. The risk of bias evaluation was used to help evaluate the quality of evidence from each study but not to exclude any studies from the review. This assessment was undertaken independently by two authors (JW and JR).

\section{Meta-analysis}

Review Manager (RevMan) 5.3 software [26] was used for a meta-analysis. Studies which were included needed to have reported HR and corresponding standard errors, or 95\% confidence intervals. The natural $\log$ of HR and standard errors (some of which were calculated from confidence intervals), were calculated for each study independently, then pooled and weighted by generic inverse variance to provide an overall HR, 95\% confidence interval, and $p$ value. The $I^{2}$ statistic (i.e. the percentage of variability between study outcomes), the chi-squared statistical test, and the corresponding $p$ value were determined automatically by the programme and displayed in a forest plot.

\section{Results}

\section{Search results}

After duplicates were removed, 215 articles were identified from the search (Fig. 1) [27].

On inspection of titles and abstracts, 156 articles were excluded as they either did not measure DNAmAge in a peripheral sample in humans and/or did not investigate 


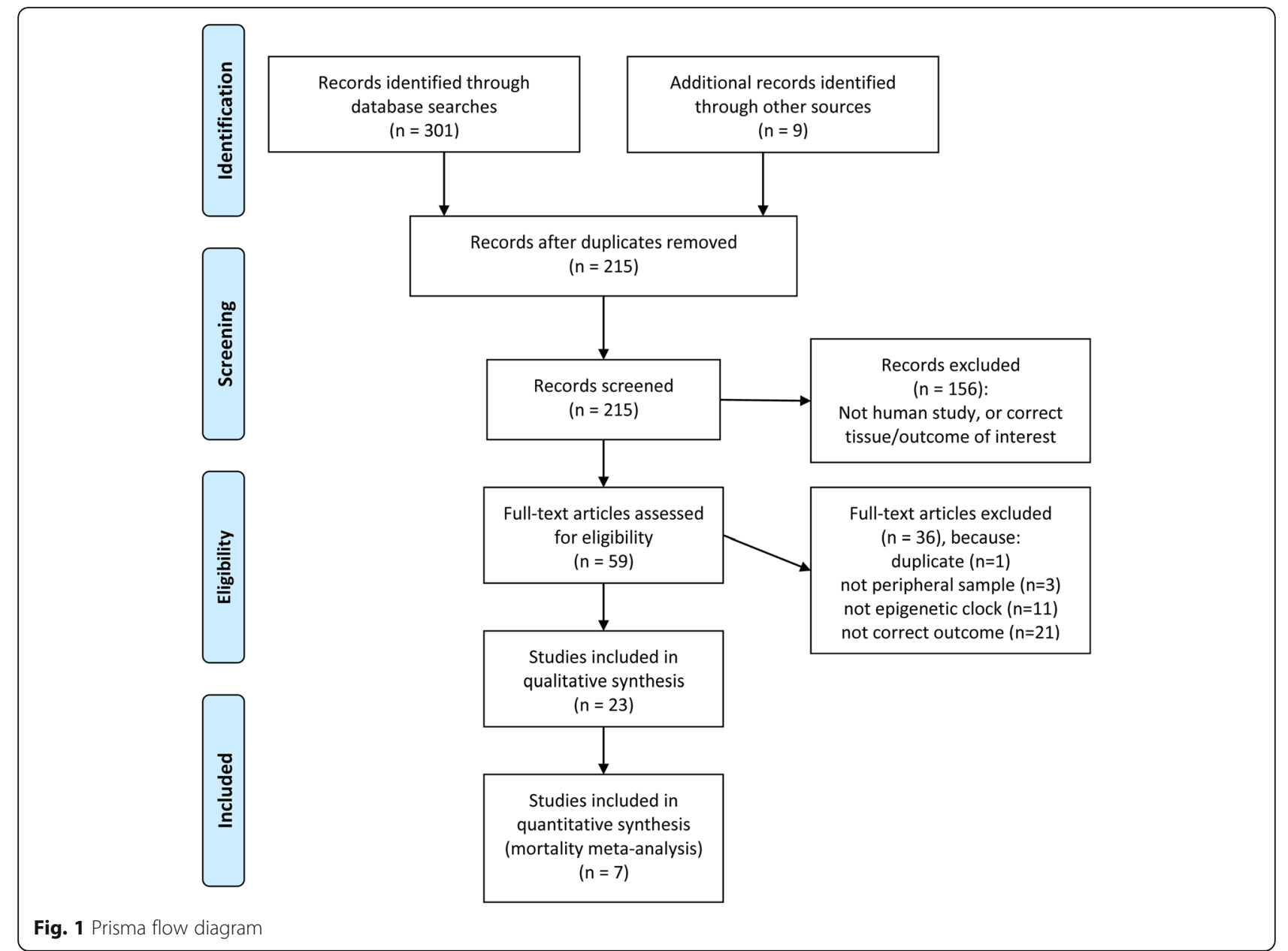

an appropriate outcome of interest. We selected 59 articles for full-text assessment.

Of these, three articles were excluded because they did not measure DNA methylation in a peripheral tissue [28-30] and 11 because they did not calculate DNAmAge using the epigenetic clock calculators that met our inclusion criteria $[6$, 31-40]. A further 21 studies were excluded because they did not measure an appropriate outcome. For example, 14 did not measure a disease outcome, mortality, or longevity [4154], 1 study investigated prevalent, not incident, diabetes [55], 2 studies examined physical frailty [44, 56], 3 studies focused on ageing-related genetic conditions [57-59] and 1 on twin differences [60]. Finally, one study was excluded because it was subsequently found to be a duplicate [61].

\section{Characteristics of included studies}

A total of 23 articles were included in this systematic review, involving 41,607 participants. For each study, we report pertinent characteristics of the study design, characteristics of the participants included, information regarding the calculation of DNAmAge, and the outcomes measured (Tables 1, 2, and 3).

\section{Study design and participants}

There were 8 case-control studies with a total of 4671 cases and 7320 controls, including participants with Parkinson's disease [16], ischemic stroke [62], and cancer [11, 13, 63, 64], as well as 2 studies of participants selected on the basis of their very old age $[65,66]$.

The remaining studies were prospective cohorts $(n=$ 29,616 participants), which included three meta-analyses $[17,18,23]$. The follow-up time in these studies varied between 3 months [67] and 21 years [18]. Overall, the studies ranged in size between 52 [68] and 12,284 participants [18]. Participants were aged between 2 [23] and 106 years [65]. Most studies included both male and female participants; however, one used data from the Women's Health Initiative (WHI) cohort of postmenopausal women [69], and one used data on only men from the US Department of Veterans Affairs' Normative Ageing Study (NAS) [70]. 


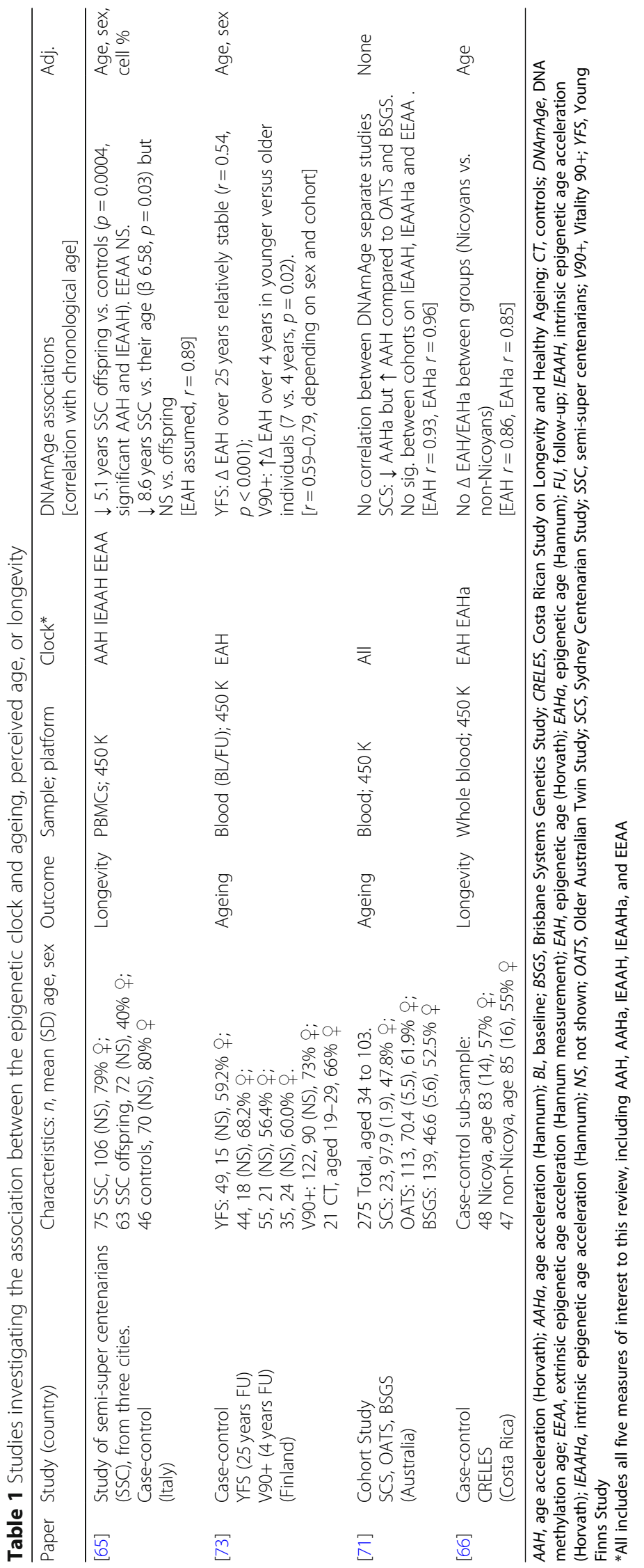




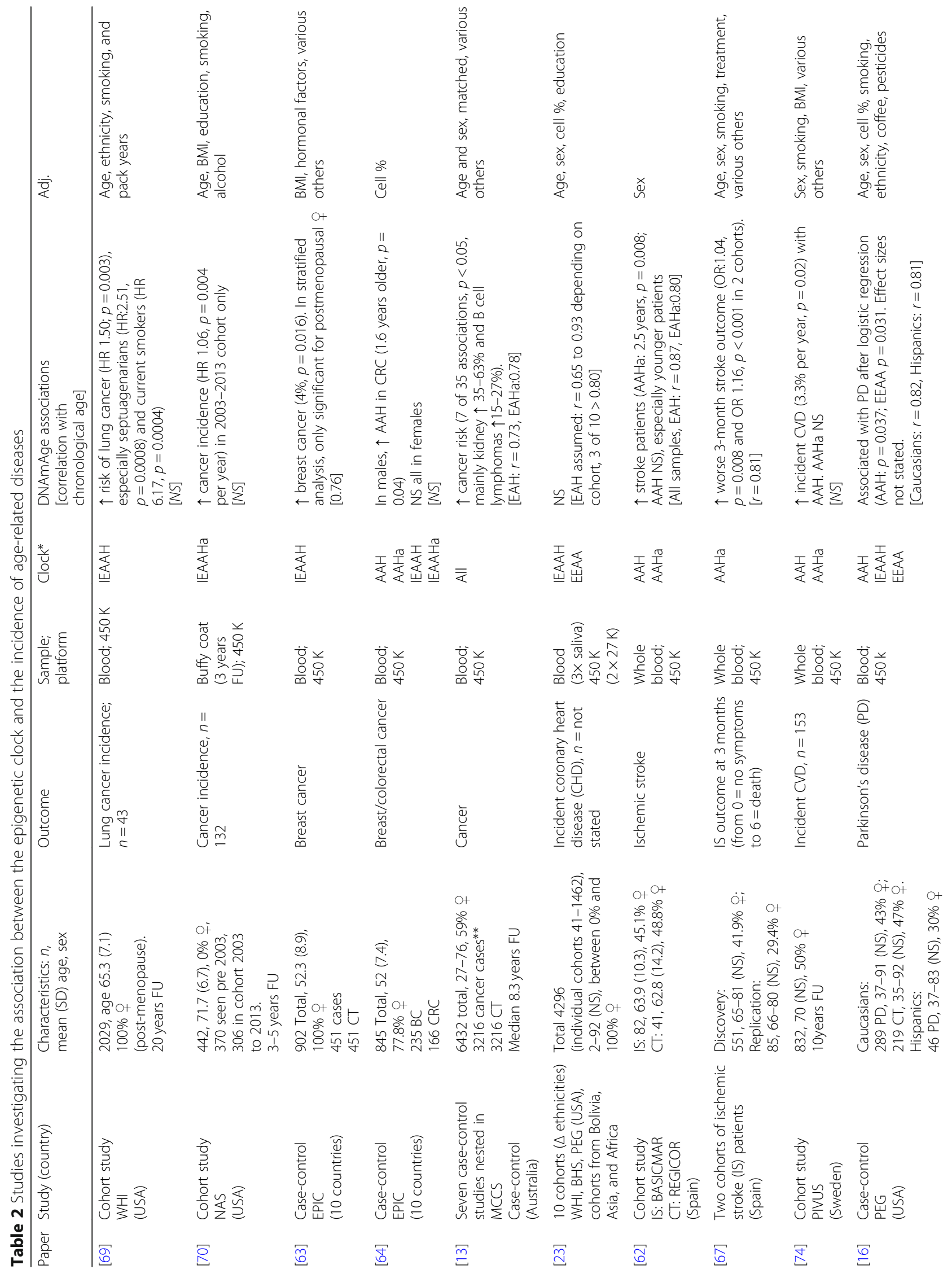




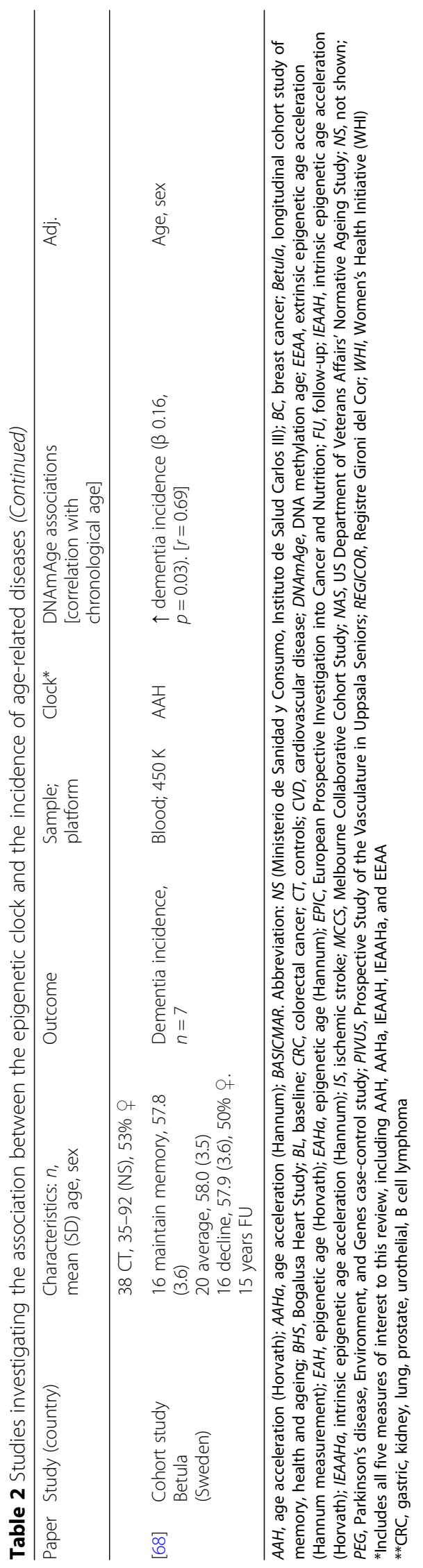




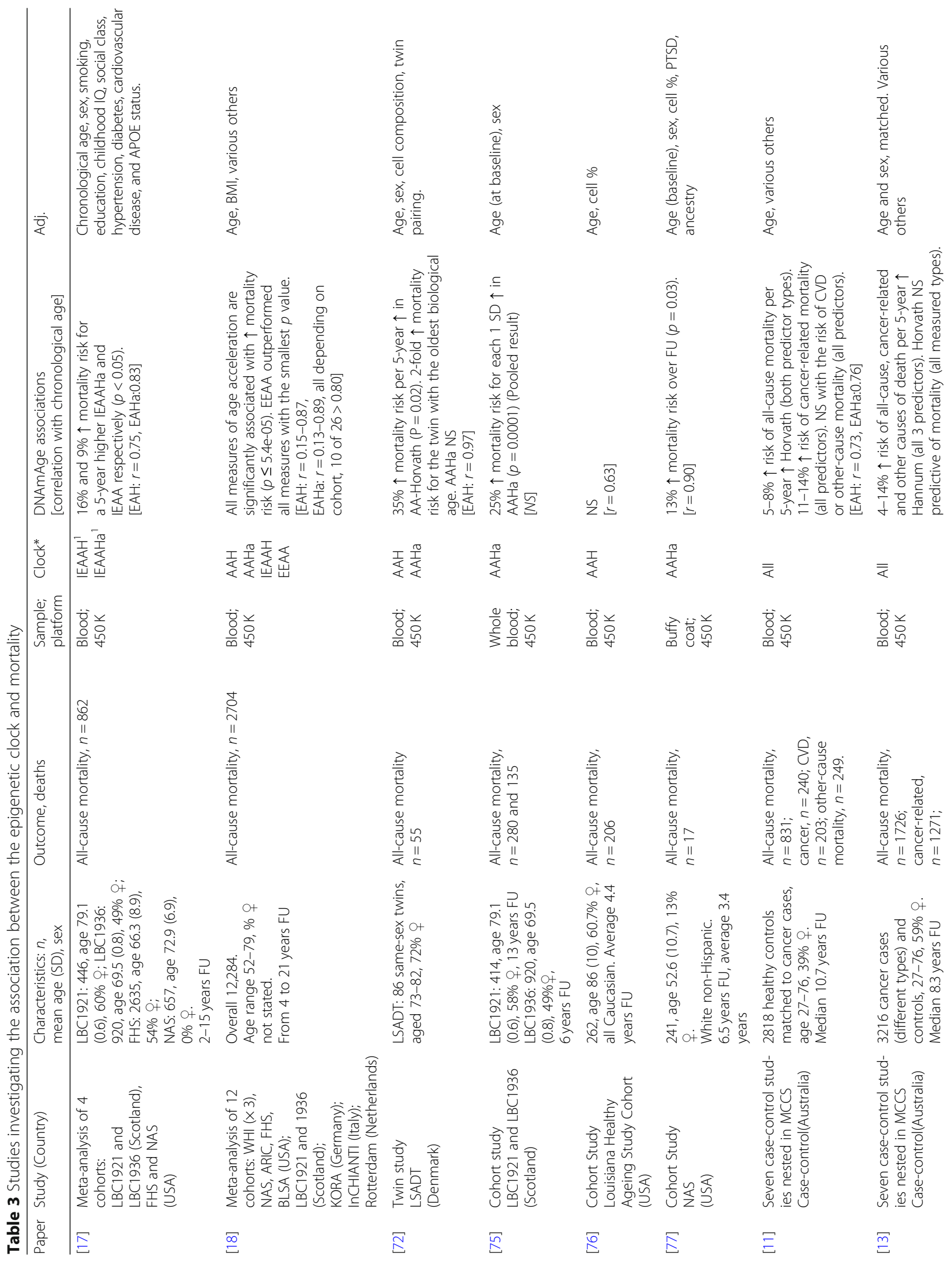




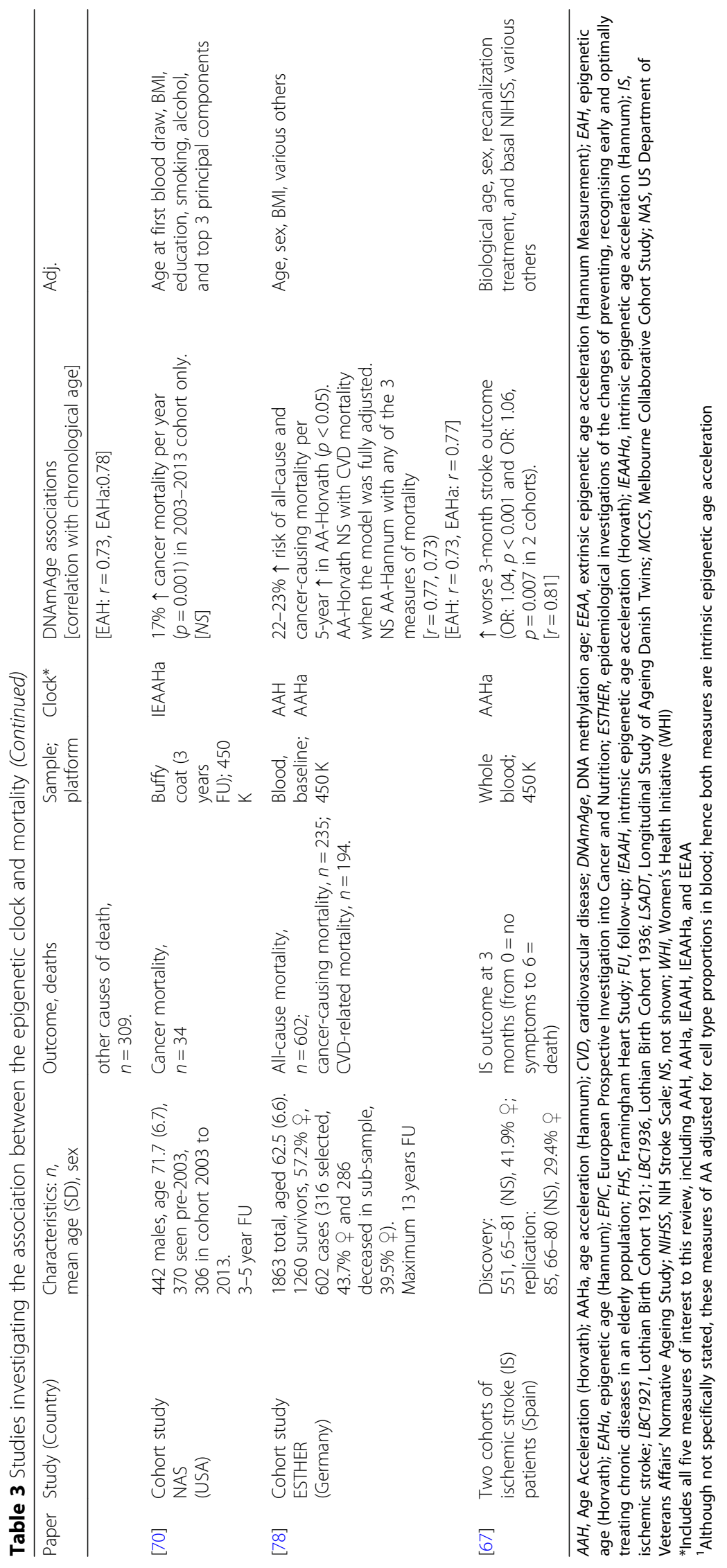




\section{Risk of bias assessment}

Eighty percent of the cohort studies (Additional file 1: Table S1) had a low risk of bias for all criteria, but only one of the eight case-control studies showed a low risk of bias (Additional file 1: Table S2) [25]. In the latter case, many of the studies provided inadequate information about whether the same criteria were used to identify cases and controls, and only half of the studies reported that cases and controls were matched. Across all study types, confounding factors were not clearly considered in the analysis of three $[66,71,72]$, two studies did not recruit all individuals from the same source population [62,71], and another two studies did not provide sufficiently clear information on source population $[16,73]$.

\section{Summary of outcomes}

\section{Longevity and ageing}

Only four studies $(n=880)$ investigated differential DNAmAge and longevity or ageing (Table 1). Two studies investigated longevity specifically $[65,66]$ and found that DNAmAge was correlated with chronological age $(r=0.89$, and $r=0.85-0.86$ respectively). Their other findings, however, varied. Horvath et al. found that semi-super centenarians have a lower DNAmAge compared to chronological age ( $\Delta-8.6$ years), and their offspring have a lower AAH and IEAAH compared to controls (but not compared to their chronological age) [65]. McEwan et al. found no age acceleration differences between long-lived Nicoyans and age-matched controls [66].

Another study investigated associations between DNAmAge and chronological age in three separate cohorts (including centenarians) [71]. When all three studies were combined, DNAmAge was highly correlated with chronological age $(r=0.93)$, but the correlation was much lower in each cohort separately $(r=0.52-0.73)$. The direction of AA was not concordant between AAH and AAHa measures across the three cohorts. The fourth study focused on long-term change in DNAmAge with ageing [73]. DNAmAge was moderately correlated with chronological age over the span of 25 years $(r=0.54)$. Younger participants aged faster (ageing seven DNA methylation years over four chronological years) than older participants.

\section{Age-related disease}

A total of 11 studies examined the association between DNAmAge and age-related diseases (Table 2). There were 5 studies of 10,650 participants that focused on cancer [13, 63, $64,69,70]$. However, two separate studies used the same cohort, and some of the participants could have been the same $[63,64]$. All studies found that increased DNAmAge (at least one of their measures) was associated with an increased risk of cancer incidence; however, the type of cancer and exact associations varied. For example, of the two studies which examined breast cancer [63, 64], only one reported a significant association [63], and the two studies of lung cancer also had discordant results $[13,69]$. On the other hand, the two studies of colorectal cancer, reported very similar findings, with $\mathrm{AAH}$ positively associated with risk $[13,64]$.

There were four studies focusing on cardiovascular-related diseases including stroke and coronary heart disease $[23,62$, $67,74]$. Two studies, authored by the same group, looked at different outcomes associated with ischemic stroke $[62,67]$. The first found an association between increased DNAmAge and ischemic stroke (AAHa +2.5 years, $p=0.008$ ) [62], and the second showed that increased DNAmAge was associated with poorer outcomes 3 months post-stroke [67]. It is not clear if the same participants were included in both studies. A large study of 4296 individuals from 10 separate cohorts did not find any evidence of an association between DNAmAge and incident coronary heart disease [23]. However, a smaller $(n=832)$ more recent study found that for every 1-year increase in DNAmAge (AAH), there was a $3.3 \%$ greater incidence of cardiovascular disease $(p=0.02)$ [74].

The remaining two studies looked at dementia $[16,68]$ and reported findings in a similar direction. Younger DNAmAge was associated with better memory, and increased DNAmAge predicted incident dementia [68]. Both AAH and EEAA were also positively associated with Parkinson's disease.

\section{Mortality}

Eleven studies (27,840 participants, 10,233 deaths) investigated the association between age acceleration and mortality (Table 3) [11, 13, 17, 18, 67, 70, 72, 75-78]. Results from 7 of the 11 studies, involving 17 individual population samples and 17,988 participants (5277 deaths), were combined to perform two independent meta-analyses (6 studies per epigenetic clock method) that investigated all-cause mortality [11, 17, 18, 72, 76-78].

Three of these studies $[17,72,78]$ measured associations using unadjusted AA, whilst two studies measured associations with all (AA, IEAA, and EEAA), or otherwise all but one (IEAAHa) of the five variations of age acceleration, previously described. The two remaining studies were included in one of the two meta-analyses, focusing on the more common measures of DNAmAge, namely, AAH and AAHa [76, 77]. The HR and SE reported from a multivariate-adjusted Cox regression model for time to death (all-cause) were used for each study.

Weighted average varied for each study and depended on the SE defined by the sample size, thus those with a larger sample size contributed the most to the resulting HR and $95 \%$ CI for each meta-analysis. Heterogeneity between and within studies was moderate to high (46\% and $67 \%$ for AAHa and AAH respectively), and a random-effects model was thus used [79]. As presented in Fig. 2a, b, a higher biological age (per 5-year increase in 


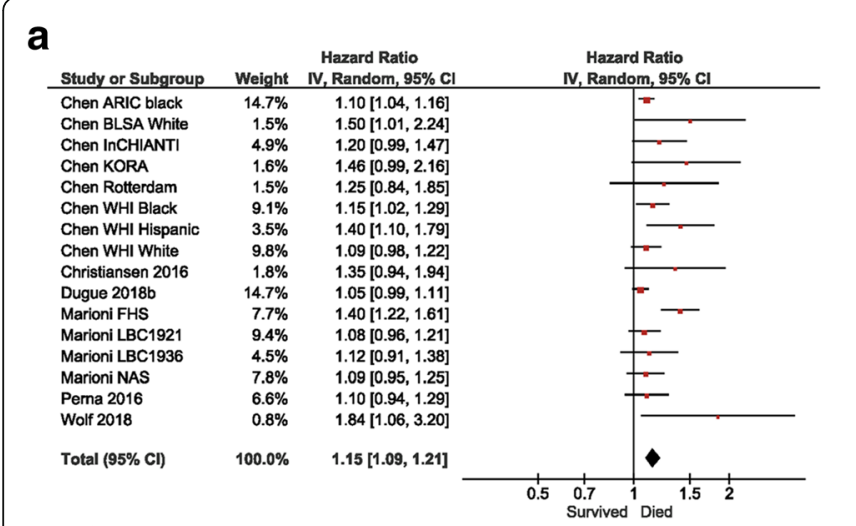

Heterogeneity: $\operatorname{Tau}^{2}=0.00 ; \mathrm{Chi}^{2}=27.97, \mathrm{df}=15(P=0.02) ; \mathbf{1}^{2}=46 \%$ Test for overall effect: $Z=5.37$ ( $P<0.00001)$

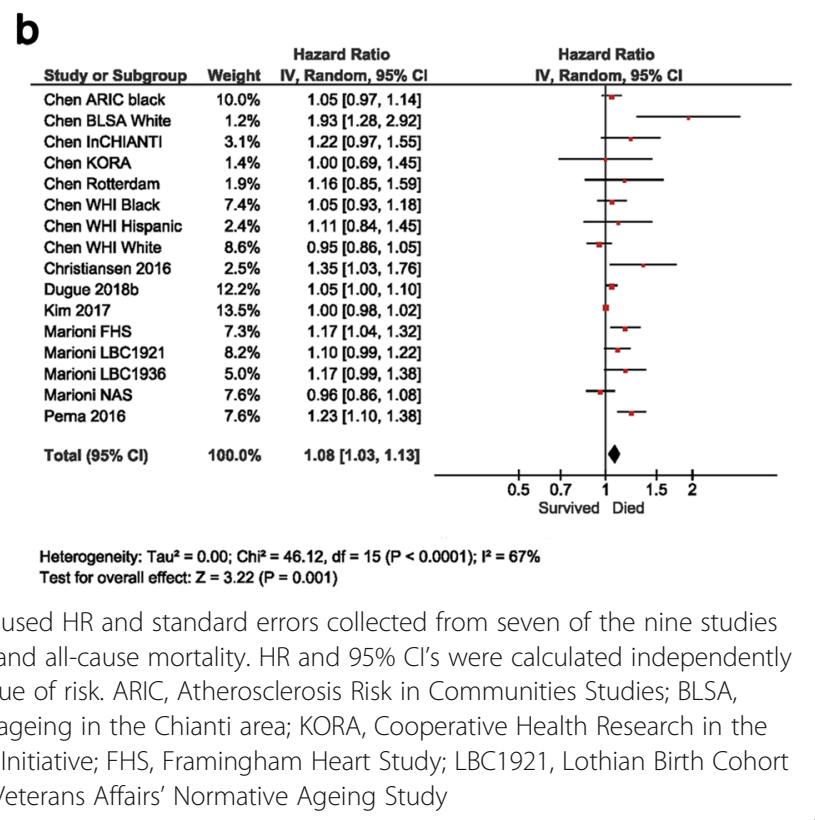

Fig. 2 Forest plots for Horvath and Hannum meta-analyses. Meta-analyses used HR and standard errors collected from seven of the nine studies measuring associations between age acceleration for a AAHa and $\mathbf{b} \mathrm{AAH}$, and all-cause mortality. HR and 95\% Cl's were calculated independently via a univariate Cox regression model and combined to provide a total value of risk. ARIC, Atherosclerosis Risk in Communities Studies; BLSA, Baltimore Longitudinal Study of Ageing; InCHIANTI, Invecchiare in Chianti, ageing in the Chianti area; KORA, Cooperative Health Research in the Augsburg Region; Rotterdam: The Rotterdam Study; WHI, Women's Health Initiative; FHS, Framingham Heart Study; LBC1921, Lothian Birth Cohort 1921; LBC1936 Lothian Birth Cohort 1936; LSADT, NAS, US Department of Veterans Affairs' Normative Ageing Study

age) was associated with an $8 \%$ and $15 \%$ increased risk of all-cause mortality for AAH and AAHa respectively.

The funnel plots for both measures were asymmetrical, indicating positive publication bias (Fig. 3). Results were similar for the two remaining studies not included in the meta-analysis $[13,75]$.

Four of the eleven studies $[11,13,70,78]$ (8339 participants, 1780 died), examined cancer-related deaths, with each reporting a significantly increased risk of cancer-related mortality in those with a higher DNAmAge. Effect sizes varied (ranging 4-23\%), and there was no obvious pattern in relation to the duration or follow-up, nor study design (case-control vs. cohort only). This contrasts with findings from the three remaining studies (3896 participants, 477 deaths) investigating associations between AA and
CVD, where a higher DNAmAge was only found to be significantly associated with an increased risk of mortality in those who had already experienced a CVD related event [67].

\section{Discussion}

\section{Main findings}

An increasing number of studies have investigated the association between DNAmAge, longevity, age-related disease, and mortality, with a total of 23 studies included in this systematic review and all published from 2015 onwards. Our primary finding is that there is sufficient evidence to support an association between accelerated DNAmAge, in particular for the Hannum epigenetic clock (AAHa), and an increased risk of all-cause mortality.

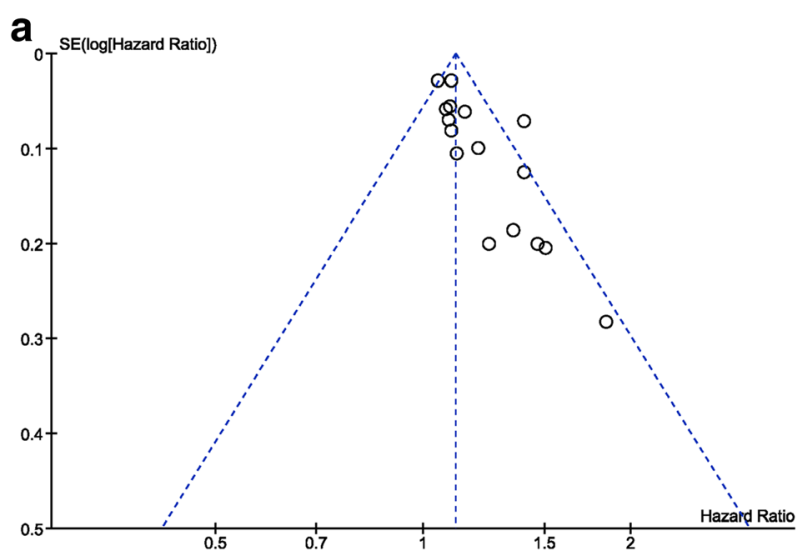

(a)

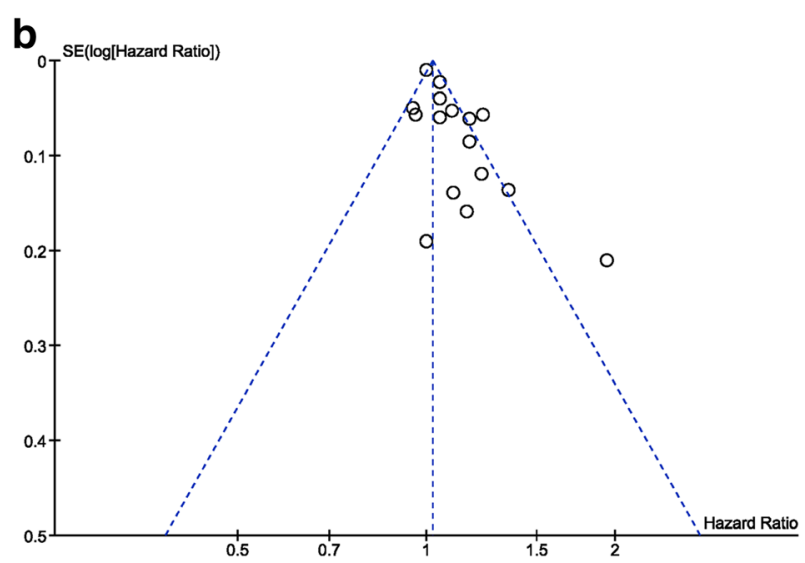

(b)

Fig. 3 Funnel plots for Horvath and Hannum meta-analyses 
The majority of studies (10 out of 11 ) independently found that a higher biological age relative to chronological age is a predictor of time-to-death, cancer-related, CVD-related, or all cause. Of these studies, two stratified by sex to determine possible differential effects $[17,18]$, and two adjusted for sex using an interaction effect with biological age $[11,78]$. Some other studies included only males [70], or females [18]. There was, however, no clear difference in the association between the epigenetic clock and the risk of death across the sexes. Likewise, findings from the two studies which considered ethnicity (as defined by country of birth or race) $[11,18]$, do not provide any evidence for differences between groups.

Collectively, these results are supported by our two meta-analyses for all-cause mortality. Interestingly, risk was greater when predicted by AAHa compared to AAH ( $15 \%$ vs. $8 \%$, respectively), a finding supported by the two meta-analyses on this topic $[17,18]$. It thus appears that these epigenetic calculators are measuring slightly different components of the ageing process. Indeed, it has been suggested that Horvath's calculator is more suited for innate process that accompany development such as puberty and menopause, whilst Hannum's may better reflect later-life diseases states and mortality [34]. Differences in the findings depending on the DNAmAge predictor used may also relate to how these algorithms were initially constructed. Specifically, Horvath's epigenetic clock algorithm was developed as a robust multi-tissue age predictor based on DNA methylation at 353 CpGs, compared with Hannum's epigenetic clock which is a blood-based estimator, defined by DNA methylation at $71 \mathrm{CpG}$ sites [80].

There were 11 studies that investigated the association between DNAmAge and age-related disease. These showed that there is some evidence, although with often varying findings, that DNAmAge might be positively associated with the incidence of age-related diseases. It was difficult to make any disease-specific comparisons, as even within disease groups, the outcomes were highly heterogeneous. For example, the two studies concerning ischemic stroke investigated different outcomes, one being ischemic stroke incidence [62], and the other being the severity of ischemic stroke outcomes at a follow-up time point [67]. However, despite different study samples and investigating various outcomes, all but one of the studies found that increased DNAmAge predicted future risk of disease. These findings are also in concordance with those for mortality, and further support the potential of DNAmAge as a global biomarker of biological ageing and health.

Finally, the association between DNAmAge and longevity remains unclear, given that we identified only four eligible studies which were all relatively small (the largest $n=257$ ). Comparisons of findings were not possible, as the scope of these studies were relatively broad, having very different study designs with unique sample characteristics. For example, one study focused on a sample from a Costa Nicoyan region of Costa Rica which is known as a hot spot of high longevity [81] and compared these individuals with non-Nicoyans. Nicoyans, however, may be ethnically different with very specific environmental exposures and lifestyle behaviours. In contrast, the other studies of longevity [65] or ageing $[71,73]$ compared small groups of individuals at various life stages, but who were selected from similar community populations. Future work in this field should focus on the study of centenarians or long-lived disease-free individuals as they may hold the answer to extended healthy lifespans. In understanding the underlying epigenetic mechanisms of ageing, such as altered DNA methylation patterns, and how it affects ageing-related genome maintenance, there is potential to directly promote healthy longevity, in turn possibly preventing age-related diseases [82].

\section{Quality and strength of the evidence}

The JBI Critical Appraisal has shown that most studies in this review were not at risk of bias (57\%). However, many studies did not report on, or were unclear about, the consistency of population, the matching of cases to controls, the selection criteria to identify cases and controls, or adjusting for possible confounding factors (43\%) (Additional file 1: Tables S1 and S2). The omission of descriptions is possibly due to many studies using several already established cohorts.

Within the 23 studies, there were a total of 41,607 participants. Although some participants clearly do overlap between studies, it is not clear to what extent. Eight individual cohorts/studies (WHI, NAS, EPIC, MCCS, PEG, BHS, LBC1921, LBC1936) were used in more than one analysis, creating a possible bias in findings, and it is thus unclear whether these studies are using the same or similar data. For example, the US Department of Veterans Affairs' Normative Ageing Study (NAS) was used in four separate studies [17, 18, 70, 77], and the Women's Health Initiative (WHI) was used in three [18, 23, 69]. Further, two studies that looked at cancer as an outcome both used the same cohort (EPIC) and had similar sample sizes $(n=$ 902 vs, $n=845$ ), but it was not clear whether the data was overlapping between both studies [63, 64].

Whilst nearly every study, apart from one [23], showed some evidence of an association between at least one of the DNAmAge measures examined and an outcome, there were few studies which were directly replicated across more than one study. The variability in these associations may be related to the different DNAmAge measures which have been used, as well as the specific outcomes. For example, the five cancer studies looked at eight specific types of cancer [70], but different cancers are known to have very specific DNA methylation patterns [83]. Whether this could also directly 
influence DNAmAge, and potentially the accuracy of this biological age predictor, is unclear.

Despite evidence pointing towards an association with all-cause mortality, the centrality of studies, observed in both funnel plots (Fig. 3) is an indication of positive publication bias, and thus caution should be taken when interpreting these findings.

\section{Accuracy of age estimation}

It has been suggested that to be an accurate biological age estimator, DNAmAge should be highly correlated with chronological age $(r \geq 0.80)$ (20 to 100 years) [80]. However, of the studies included in this systematic review, only 8 of the 23 studies reported a correlation between DNAmAge and chronological age at or above this level. Ten studies had either $r<0.80$ on at least one measure of DNAmAge (either Horvath or Hannum) or had a lower correlation for all measures $(r=0.13-0.79)$. If DNAmAge is not highly correlated with chronological age, then the measures of age acceleration may also be less accurate. One of the reasons for this may be that most of the included studies focused on a narrow age range of older individuals, whilst the epigenetic clock algorithms were developed for individuals across a wide spectrum of ages (from 0 to 100 years). The lower correlations may also suggest that the measured DNAmAge of participants are being confounded by environmental factors beyond what studies have adjusted for. This is a particularly important point, given that DNA methylation levels are dynamic and may be influenced by environmental factors such as stress [84] and smoking [85].

\section{Strengths and limitations of the review}

This systematic review was conducted in line with the Preferred Reporting Items for Systematic Reviews and Meta-Analyses (PRISMA) guidelines. A systematic search was established with clear inclusion and exclusion criteria, and for all studies included, the quality of evidence was evaluated. A meta-analysis was performed by pooling the data of multiple studies, giving greater certainty to the results. However, for both Horvath and Hannum methods, studies showed a moderate to high amount of heterogeneity, suggesting that studies were not undertaken in the same way or that different experimental protocols were applied. Heterogeneity may also be the result of including studies with varying cohorts, for example, the pooling of data from same-sex twins, combined with a male-only study, and a population study. As previously stated, funnel plots suggest that there was publication bias.

Limitations to our systematic review are that only studies assessing either the Horvath and/or Hannum epigenetic clocks were included, which are the most commonly used measures. However, there are a number of newer DNA methylation age estimators that have also been developed.
For example, a recent 'phenotypic age estimator' was developed [34] which shows very good predictive accuracy for time to death in association with a number of markers of immunosenescence and smoking status.

It remains unclear whether these methylation changes at specific $\mathrm{CpGs}$ are driving ageing or are consequences of the ageing process (cellular ageing, underlying disease processes). Whilst larger sets of CpGs can produce more precise estimations of age [80], many measures in this review only showed modest or weak associations with chronological age. A meta-analysis could not be undertaken in regard to longevity or age-related disease as studies were too few and measures and outcomes too heterogeneous.

Whilst measures of biological age and their associations with mortality are more certain, the clinical practicality of measuring DNAmAge proves to be problematic, for example, when compared to physical tests that are also able to predict mortality, such as walking speed, grip strength, and BMI measurements, which are cheaper and far easier to obtain [86]. Should the cost of measuring DNAmAge come down significantly, it would be a viable measure of risk for all-cause mortality. These studies may provide practical suggestions for obtaining healthy longevity through the active modification of DNA methylation patterns by changing lifestyle habits. Both these, and focusing on modifying age-related, disease specific DNA methylation profiles may also aid in decreasing incidence of age-related disease or early mortality.

\section{Recommendations for future studies}

In designing future studies in this field, some of the following points should be considered. Cohort studies are preferred over case-controls, with the latter being more susceptible to bias as we identified in this review. Cases and controls must be sampled from the same source population and sufficiently well matched. Thorough phenotyping of the study population more generally is also essential. This helps rule out competing exposures or diseases which may also confound the associations. Somewhat surprisingly, there was a lack of evidence for sex- or ethnic-specific effects observed in this systematic review, but future studies should also consider analysing and reporting this data individually. Longitudinal studies, that follow individuals over time and track disease progression, together with biological samples taken at several time points, would have the greatest value and could shed light on whether DNA methylation changes are driving ageing and age-related disease, or if they are the consequence of these processes.

In terms of reporting results, it is essential that studies provide comprehensive details relating to the participant's characteristics, and present all data analysis that has been undertaken. Replication and validation of findings across multiple independent samples or cohorts are crucial. This will help reduce the reporting of false-positive findings. 
Finally, the epigenetic clocks included in this review (Horvath and Hannum) were developed to measure biological age across a wide range of chronological ages. It could be that there is greater utility in developing an epigenetic clock specifically for later life that could encapsulate the lifetime exposure to a range of environmental factors and the increased prevalence of comorbidities. This may also be the period of the lifespan where predicting the risk of disease and mortality could be particularly pertinent in terms of interventions/treatments or prevention.

\section{Conclusion}

Some measures of biological age presented in this systematic review may reflect longevity in long-lived individuals and risk of age-related disease. However, due to the relatively small number of studies and variability in findings, the evidence is as yet insufficient to confirm the utility of DNAmAge as a clinical biomarker in this regard.

DNAmAge is one of the most highly studied markers of ageing [87], and, with the limitations discussed here, appears to be a good predictor of mortality. An accurate measure of DNAmAge, that in theory could be measured at any age, has great potential to be an early biomarker of disease risk. Identifying individuals with accelerated biological ageing could permit targeted interventions to help delay their risk of age-related disease and increase their overall health. With the ageing population, there is increasing emphasis on promoting the health and well-being of older individuals. Given its importance, multiple studies into specific outcomes, with a wider assortment of study cohorts, should be explored further.

Given that DNA methylation is an epigenetic mechanism involved in gene regulation, beyond the ability to estimate future risk of disease and mortality, further studies could provide novel insights into the long-standing question about why and how people age. They may also offer answers as to how we may prevent the negative effects of ageing such as age-related diseases. Thus, it is of particular importance in future studies not only to measure DNAmAge, but also to investigate which interventions (e.g. lifestyle changes) attenuate the advancement or initiate the reversal of biological age directly.

\section{Additional files}

Additional file 1: Table S1. Critical appraisal of cohort studies included in the review, using relevant criteria from the JBI Critical Appraisal Checklist [1]. Table S2. Critical appraisal of case-control studies included in the review, using relevant criteria from the JBI Critical Appraisal Checklist [1]. (DOCX $93 \mathrm{~kb}$ )

Additional file 2: Supplimentary MetaData from meta-analysis. (XLSX $12 \mathrm{~kb})$

\section{Abbreviations}

AA: Age acceleration; AAH: Age acceleration calculated with Horvath's clock; AAHa: Age acceleration calculated with Hannum's clock; BHS: Bogalusa Heart study; CpG: Cytosine-phosphate-guanine; CVD: Cardiovascular diseases;

DNAmAge: DNA methylation age; EEAA: Extrinsic epigenetic age acceleration calculated with Hannum's clock; EPIC: European Prospective Investigation into Cancer and Nutrition; IEAAH: Intrinsic epigenetic age acceleration calculated with Horvath's clock; IEAAHa: Intrinsic epigenetic age acceleration calculated with Hannum's clock; JBI: Joanna Briggs Institute;

LBC1921: Lothian Birth Cohort 1921; LBC1936: Lothian Birth Cohort 1936; MCCS: Melbourne Collaborative Cohort Study; NAS: US Department of Veterans Affairs' Normative Ageing Study; PEG: Parkinson's disease, Environment, and Genes case-control study; PRISMA: Preferred Reporting Items for Systematic Reviews and Meta-Analyses; WHI: Women's Health Initiative

\section{Acknowledgements}

P.F. is the recipient of a Research Training Program stipend PhD scholarship, awarded by Monash University and the Australian Government. The funders had no role in the study design; collection, analysis, and interpretation of data; writing of the report; and decision to submit the article for publication.

\section{Funding}

No funding was involved in the preparation of this manuscript.

Availability of data and materials

All data collected, generated or analysed during this study are included in this published article, or available as meta data [Additional file 2].

\section{Authors' contributions}

$J R$ undertook the initial systematic search and screening of the literature. JR, $J W$, and PF collected and tabulated the data within this manuscript. PF and JW summarised the findings from articles. JW carried out meta-analyses. PF, $J W$, and JR were major contributors in writing the manuscript. RW and ME oversaw additional input and revisions to manuscript drafts. All authors read and approved the final manuscript.

\section{Ethics approval and consent to participate}

Ethics approval was given within each individual study included in this review.

\section{Consent for publication}

Not applicable.

\section{Competing interests}

The authors declare that they have no competing interests.

\section{Publisher's Note}

Springer Nature remains neutral with regard to jurisdictional claims in published maps and institutional affiliations.

\section{Author details}

${ }^{1}$ Department of Epidemiology and Preventive Medicine, Monash University, ASPREE, Level 5, The Alfred Centre, 99 Commercial Road, Melbourne, Victoria 3004, Australia. 'Disease Epigenetics, Murdoch Childrens Research Institute, The University of Melbourne, Parkville, Victoria 3052, Australia. ${ }^{3}$ INSERM, U1061, Neuropsychiatrie, Recherche Clinique et Epidémiologique, Neuropsychiatry: Research Epidemiological and Clinic, Université Montpellier, 34000 Montpellier, France. ${ }^{4}$ Department of Pharmacy Practice and Science, College of Pharmacy, The University of lowa, lowa City, IA, USA. ${ }^{5}$ Department of Family Medicine, Carver College of Medicine, The University of lowa, lowa City, IA, USA.

Received: 22 December 2018 Accepted: 25 March 2019

Published online: 11 April 2019

\section{References}

1. Ho JY, Hendi AS. Recent trends in life expectancy across high income countries: retrospective observational study. BMJ (Clinical research ed). 2018; $362: k 2562$. 
2. Kontis V, Bennett JE, Mathers CD, Li G, Foreman K, Ezzati M. Future life expectancy in 35 industrialised countries: projections with a Bayesian model ensemble. Lancet (London, England). 2017;389(10076):1323-35.

3. Stambler I, Jin K, Lederman S, Barzilai N, Olshansky SJ, Omokaro E, Barratt J, Anisimov VN, Rattan S, Yang S, et al. Aging health and R\&D for healthy longevity must be included into the WHO work program. Aging Dis. 2018; 9(2):331-3.

4. Lopez-Otin C, Blasco MA, Partridge L, Serrano M, Kroemer G. The hallmarks of aging. Cell. 2013;153(6):1194-217.

5. Fraga MF, Ballestar E, Paz MF, Ropero S, Setien F, Ballestar ML, Heine-Suner D, Cigudosa JC, Urioste M, Benitez J, et al. Epigenetic differences arise during the lifetime of monozygotic twins. Proc Natl Acad Sci U S A. 2005; 102(30):10604-9.

6. Slieker RC, van Iterson M, Luijk R, Beekman M, Zhernakova DV, Moed MH, Mei H, van Galen M, Deelen P, Bonder MJ, et al. Age-related accrual of methylomic variability is linked to fundamental ageing mechanisms. Genome Biol. 2016;17(1):191.

7. Hannum G, Guinney J, Zhao L, Zhang L, Hughes G, Sadda S, Klotzle B, Bibikova M, Fan JB, Gao Y, et al. Genome-wide methylation profiles reveal quantitative views of human aging rates. Mol Cell. 2013;49(2):359-67.

8. Horvath S. DNA methylation age of human tissues and cell types. Genome Biol. 2013;14(10):R115.

9. Jylhava J, Pedersen NL, Hagg S. Biological age predictors. EBioMedicine. 2017;21:29-36

10. Lee HY, Lee SD, Shin K-J. Forensic DNA methylation profiling from evidence material for investigative leads. BMB Rep. 2016;49(7):359-69.

11. Dugue PAB, Bassett JK, Joo JE, Baglietto L, Jung CH, Wong EM, Fiorito G, Schmidt D, Makalic E, Li S, et al. Association of DNA methylation-based biological age with health risk factors and overall and cause-specific mortality. Am J Epidemiol. 2018;187(3):529-38.

12. Gale CR, Marioni RE, Harris SE, Starr JM, Deary IJ. DNA methylation and the epigenetic clock in relation to physical frailty in older people: the Lothian Birth Cohort 1936. Clin Epigenetics. 2018;10(1):101.

13. Dugue PA, Bassett JK, Joo JE, Jung $\mathrm{CH}$, Ming Wong E, Moreno Betancur M, Schmidt D, Makalic E, Li S, Severi G, et al. DNA methylation-based biological aging and cancer risk and survival: pooled analysis of seven prospective studies. Int J Cancer. 2018; 142(8):1611-9.

14. Grant CD, Jafari N, Hou L, Li Y, Stewart JD, Zhang G, Lamichhane A, Manson JE, Baccarelli AA, Whitsel EA, et al. A longitudinal study of DNA methylation as a potential mediator of age-related diabetes risk. Geroscience. 2017;39(5-6):475-89.

15. Roetker NS, Pankow JS, Bressler J, Morrison AC, Boerwinkle E. Prospective Study of Epigenetic Age Acceleration and Incidence of Cardiovascular Disease Outcomes in the ARIC Study (Atherosclerosis Risk in Communities). Circ Genom Precis Med. 2018;11(3):e001937.

16. Horvath S, Ritz BR. Increased epigenetic age and granulocyte counts in the blood of Parkinson's disease patients. Aging (Albany NY). 2015;7(12):1130-42.

17. Marioni RE, Shah S, McRae AF, Chen BH, Colicino E, Harris SE, Gibson J, Henders AK, Redmond P, Cox SR, et al. DNA methylation age of blood predicts all-cause mortality in later life. Genome Biol. 2015; 16:25

18. Chen BH, Marioni RE, Colicino E, Peters MJ, Ward-Caviness CK, Tsai PC, Roetker NS, Just AC, Demerath EW, Guan W, et al. DNA methylation-based measures of biological age: meta-analysis predicting time to death. Aging (Albany NY). 2016; 8(9):1844-65

19. Booth A, Clarke M, Ghersi D, Moher D, Petticrew M, Stewart L. An international registry of systematic-review protocols. Lancet (London, England). 2011;377(9760):108-9.

20. Moher D, Liberati A, Tetzlaff J, Altman DG. Preferred reporting items for systematic reviews and meta-analyses: the PRISMA statement. International journal of surgery (London, England). 2010;8(5):336-41.

21. Moher D, Shamseer L, Clarke M, Ghersi D, Liberati A, Petticrew M, Shekelle $P$, Stewart LA. Preferred reporting items for systematic review and meta-analysis protocols (PRISMA-P) 2015 statement. Systematic reviews. 2015;4:1.

22. Horvath S. DNA Methylation Age Calculator. https://dnamage.genetics.ucla. edu/home. Accessed 1 Nov 2018

23. Horvath S, Gurven M, Levine ME, Trumble BC, Kaplan H, Allayee H, Ritz BR, Chen B, Lu AT, Rickabaugh TM, et al. An epigenetic clock analysis of race/ ethnicity, sex, and coronary heart disease. Genome Biol. 2016;17(1):171.
24. Valiathan $R$, Ashman M, Asthana D. Effects of ageing on the immune system: infants to elderly. Scand J Immunol. 2016;83(4):255-66.

25. The Joanna Briggs Institute. Joanna Briggs Institute Reviewers' Manual: 2014 edition. Adelaide: The Joanna Briggs Institute; 2014.

26. Review Manager (RevMan) [Computer Program]. Version 5.3. Copenhagen: The Nordic Cochrane Center, The Cochrane Collaboration; 2014.

27. Moher D, Liberati A, Tetzlaff J, Altman DG, The PG. Preferred reporting items for systematic reviews and Meta-analyses: The PRISMA statement. PLoS Med. 2009;6(7):e1000097.

28. Lin QWW. Epigenetic aging signatures are coherently modified in cancer. PLoS Genet. 2015;11(6):e1005334

29. Nazarenko MS, Markov AV, Lebedev IN, Freidin MB, Sleptcov AA, Koroleva IA, Frolov AV, Popov VA, Barbarash OL, Puzyrev VP. A comparison of genome-wide DNA methylation patterns between different vascular tissues from patients with coronary heart disease. PLoS One. 2015;10(4):e0122601.

30. Vidal-Bralo L, Lopez-Golan Y, Mera-Varela A, Rego-Perez I, Horvath S, Zhang Y, Del Real A, Zhai G, Blanco FJ, Riancho JA, et al. Specific premature epigenetic aging of cartilage in osteoarthritis. Aging (Albany NY). 2016;8(9): 2222-31.

31. Florian MC, Klenk J, Marka G, Soller K, Kiryakos H, Peter R, Herbolsheimer F, Rothenbacher D, Denkinger M, Geiger $\mathrm{H}$. Expression and activity of the small RhoGTPase Cdc42 in blood cells of older adults are associated with age and cardiovascular disease. J Gerontol A Biol Sci Med Sci. 2017;72(9):1196-200.

32. Han LKM, Aghajani M, Clark SL, Chan RF, Hattab MW, Shabalin AA, Zhao M, Kumar G, Xie LY, Jansen R, et al. Epigenetic aging in major depressive disorder. Am J Psychiatry. 2018;175(8):774-82.

33. Jeremian R, Chen YA, De Luca V, Vincent JB, Kennedy JL, Zai CC, Strauss J. Investigation of correlations between DNA methylation, suicidal behavior and aging. Bipolar Disord. 2017;19(1):32-40.

34. Levine ME, Lu AT, Quach A, Chen BH, Assimes TL, Bandinelli S, Hou L, Baccarelli AA, Stewart JD, Li Y, et al. An epigenetic biomarker of aging for lifespan and healthspan. Aging (Albany NY). 2018;10(4):573-91.

35. Nelson KN, Hui Q, Rimland D, Xu K, Freiberg MS, Justice AC, Marconi VC, Sun YV. Identification of HIV infection-related DNA methylation sites and advanced epigenetic aging in HIV-positive, treatment-naive U.S. veterans. Aids. 2017:31(4):571-5.

36. Townsend TA, Parrish MC, Engelward BP, Manjanatha MG. The development and validation of EpiComet-Chip, a modified high-throughput comet assay for the assessment of DNA methylation status. Environ Mol Mutagen. 2017; 58(7):508-21.

37. Weidner Cl, Lin Q, Koch CM, Eisele L, Beier F, Ziegler P, Bauerschlag DO, Jockel KH, Erbel R, Muhleisen TW, et al. Aging of blood can be tracked by DNA methylation changes at just three CpG sites. Genome Biol. 2014:15(2):R24.

38. Wilhelm T. Phenotype prediction based on genome-wide DNA methylation data. BMC Bioinformatics. 2014;15:193.

39. Zhang Y, Hapala J, Brenner H, Wagner W. Individual CpG sites that are associated with age and life expectancy become hypomethylated upon aging. Clin Epigenetics. 2017;9:9.

40. Fernandez-Rebollo E, Eipel M, Seefried L, Hoffmann P, Strathmann K, Jakob F, Wagner W. Primary osteoporosis is not reflected by disease-specific DNA methylation or accelerated epigenetic age in blood. J Bone Miner Res. 2018;33(2):356-61.

41. Brody GH, Yu T, Chen E, Beach SR, Miller GE. Family-centered prevention ameliorates the longitudinal association between risky family processes and epigenetic aging. J Child Psychol Psychiatry. 2016;57(5):566-74

42. Carroll JE, Irwin MR, Levine M, Seeman TE, Absher D, Assimes T, Horvath S. Epigenetic aging and immune senescence in women with insomnia symptoms: findings from the Women's Health Initiative study. Biol Psychiatry. 2017;81(2):136-44.

43. El Hajj N, Haertle L, Dittrich M, Denk S, Lehnen H, Hahn T, Schorsch M, Haaf T. DNA methylation signatures in cord blood of ICSI children. Hum Reprod. 2017:32(8):1761-9

44. Gale CR, Marioni RE, Cukic I, Chastin SF, Dall PM, Dontje ML, Skelton DA, Deary IJ. The epigenetic clock and objectively measured sedentary and walking behavior in older adults: the Lothian birth cohort 1936. Clin Epigenetics. 2018;10:4.

45. Gao X, Zhang Y, Breitling LP, Brenner H. Relationship of tobacco smoking and smoking-related DNA methylation with epigenetic age acceleration. Oncotarget. 2016;7(30):46878-89. 
46. Gao X, Zhang Y, Brenner H. Associations of helicobacter pylori infection and chronic atrophic gastritis with accelerated epigenetic ageing in older adults. Br J Cancer. 2017;117(8):1211-4.

47. Gross AM, Jaeger PA, Kreisberg JF, Licon K, Jepsen KL, Khosroheidari M, Morsey BM, Swindells S, Shen $\mathrm{H}, \mathrm{Ng} C T$, et al. Methylome-wide analysis of chronic HIV infection reveals five-year increase in biological age and epigenetic targeting of HLA. Mol Cell. 2016;62(2):157-68.

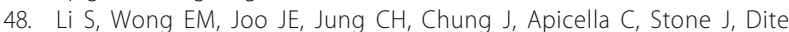
GS, Giles GG, Southey MC, et al. Genetic and environmental causes of variation in the difference between biological age based on DNA methylation and chronological age for middle-aged women. Twin Res Hum Genet. 2015;18(6):720-6.

49. McCartney DL, Stevenson AJ, Walker RM, Gibson J, Morris SW, Campbell A, Murray AD, Whalley HC, Porteous DJ, Mclntosh AM, et al. Investigating the relationship between DNA methylation age acceleration and risk factors for Alzheimer's disease. Alzheimer's \& dementia (Amsterdam, Netherlands). 2018;10:429-37.

50. Starnawska A, Tan Q, Lenart A, McGue M, Mors O, Borglum AD, Christensen $K$, Nyegaard M, Christiansen L. Blood DNA methylation age is not associated with cognitive functioning in middle-aged monozygotic twins. Neurobiol Aging. 2017:50:60-3.

51. Suarez A, Lahti J, Czamara D, Lahti-Pulkkinen M, Girchenko P, Andersson S, Strandberg TE, Reynolds RM, Kajantie E, Binder EB, et al. The epigenetic clock and pubertal, neuroendocrine, psychiatric, and cognitive outcomes in adolescents. Clin Epigenetics. 2018;10(1):96.

52. Suarez A, Lahti J, Czamara D, Lahti-Pulkkinen M, Knight AK, Girchenko P, Hamalainen E, Kajantie E, Lipsanen J, Laivuori H, et al. The epigenetic clock at birth: associations with maternal antenatal depression and child psychiatric problems. J Am Acad Child Adolesc Psychiatry. 2018;57(5):321-8.e2

53. Walker RF, Liu JS, Peters BA, Ritz BR, Wu T, Ophoff RA, Horvath S. Epigenetic age analysis of children who seem to evade aging. Aging (Albany NY) 2015;7(5):334-9.

54. Horvath S, Erhart W, Brosch M, Ammerpohl O, von Schonfels W, Ahrens M, Heits N, Bell JT, Tsai PC, Spector TD, et al. Obesity accelerates epigenetic aging of human liver. Proc Natl Acad Sci U S A. $2014 ; 111(43): 15538-43$.

55. Irvin MR, Aslibekyan S, Do A, Zhi D, Hidalgo B, Claas SA, Srinivasasainagendra V, Horvath S, Tiwari HK, Absher DM, et al. Metabolic and inflammatory biomarkers are associated with epigenetic aging acceleration estimates in the GOLDN study. Clin Epigenetics. 2018;10(1) (no pagination):56.

56. Breitling LP, Saum KU, Perna L, Schottker B, Holleczek B, Brenner H. Frailty is associated with the epigenetic clock but not with telomere length in a German cohort. Clin Epigenetics. 2016:8:21.

57. Horvath S, Garagnani P, Bacalini MG, Pirazzini C, Salvioli S, Gentilini D, Di Blasio AM, Giuliani C, Tung S, Vinters HV, et al. Accelerated epigenetic aging in Down syndrome. Aging Cell. 2015;14(3):491-5.

58. Maierhofer A, Flunkert J, Oshima J, Martin GM, Haaf T, Horvath S. Accelerated epigenetic aging in Werner syndrome. Aging (Albany NY). 2017; 9(4):1143-52.

59. Zhang M, Tartaglia MC, Moreno D, Sato C, McKeever P, Weichert A, Keith J, Robertson J, Zinman L, Rogaeva E. DNA methylation age-acceleration is associated with disease duration and age at onset in C9orf72 patients. Acta Neuropathol. 2017;134(2):271-9.

60. Debrabant B, Soerensen M, Christiansen L, Tan Q, McGue M, Christensen K, Hjelmborg J. DNA methylation age and perceived age in elderly Danish twins. Mech Ageing Dev. 2018;169:40-4.

61. Mather KA, Armstrong NJ, Thalamuthu A, Kwok JB. Tick tock: DNA methylation, the epigenetic clock and exceptional longevity. Epigenomics. 2016;8(12):1577-82.

62. Soriano-Tarraga C, Giralt-Steinhauer E, Mola-Caminal M, VivancoHidalgo RM, Ois A, Rodriguez-Campello A, Cuadrado-Godia E, SayolsBaixeras S, Elosua R, Roquer J, et al. Ischemic stroke patients are biologically older than their chronological age. Aging (Albany NY). 2016;8(11):2655-66.

63. Ambatipudi S, Horvath S, Perrier F, Cuenin C, Hernandez-Vargas $H$, Le Calvez-Kelm F, Durand G, Byrnes G, Ferrari P, Bouaoun L, et al. DNA methylome analysis identifies accelerated epigenetic ageing associated with postmenopausal breast cancer susceptibility. Eur J Cancer. 2017;75:299-307
64. Durso DF, Bacalini MG, Sala C, Pirazzini C, Marasco E, Bonafe M, do Valle IF, Gentilini D, Castellani G, Faria AMC, et al. Acceleration of leukocytes' epigenetic age as an early tumor and sex-specific marker of breast and colorectal cancer. Oncotarget. 2017:8(14): 23237-45.

65. Horvath S, Pirazzini C, Bacalini MG, Gentilini D, Di Blasio AM, Delledonne M, Mari D, Arosio B, Monti D, Passarino G, et al. Decreased epigenetic age of PBMCs from Italian semi-supercentenarians and their offspring. Aging (Albany NY). 2015;7(12):1159-70.

66. McEwen LM, Morin AM, Edgar RD, Maclsaac JL, Jones MJ, Dow WH, Rosero-Bixby L, Kobor MS, Rehkopf DH. Differential DNA methylation and lymphocyte proportions in a Costa Rican high longevity region. Epigenetics Chromatin. 2017;10:21.

67. Soriano-Tarraga C, Mola-Caminal M, Giralt-Steinhauer E, Ois A, RodriguezCampello A, Cuadrado-Godia E, Gomez-Gonzalez A, Vivanco-Hidalgo RM, Fernandez-Cadenas I, Cullell N, et al. Biological age is better than chronological as predictor of 3-month outcome in ischemic stroke. Neurology. 2017;89(8):830-6.

68. Degerman S, Josefsson M, Nordin Adolfsson A, Wennstedt S, Landfors M, Haider Z, Pudas S, Hultdin M, Nyberg L, Adolfsson R. Maintained memory in aging is associated with young epigenetic age. Neurobiol Aging. 2017;55:167-71

69. Levine ME, Hosgood HD, Chen B, Absher D, Assimes T, Horvath S. DNA methylation age of blood predicts future onset of lung cancer in the women's health initiative. Aging (Albany NY). 2015;7(9):690-700.

70. Zheng Y, Joyce BT, Colicino E, Liu L, Zhang W, Dai Q, Shrubsole MJ, Kibbe WA, Gao T, Zhang Z, et al. Blood epigenetic age may predict Cancer incidence and mortality. EBioMedicine. 2016;5:68-73.

71. Armstrong NJ, Mather KA, Thalamuthu A, Wright MJ, Trollor JN, Ames D, Brodaty H, Schofield PR, Sachdev PS, Kwok JB. Aging, exceptional longevity and comparisons of the Hannum and Horvath epigenetic clocks. Epigenomics. 2017;9(5):689-700.

72. Christiansen L, Lenart A, Tan Q, Vaupel JW, Aviv A, McGue M, Christensen K. DNA methylation age is associated with mortality in a longitudinal Danish twin study. Aging Cell. 2016;15(1):149-54.

73. Kananen L, Marttila S, Nevalainen T, Kummola L, Junttila I, Mononen N, Kahonen M, Raitakari OT, Hervonen A, Jylha M, et al. The trajectory of the blood DNA methylome ageing rate is largely set before adulthood: evidence from two longitudinal studies. Age (Dordr). 2016;38(3):65

74. Lind L, Ingelsson E, Sundstrom J, Siegbahn A, Lampa E. Methylation-based estimated biological age and cardiovascular disease. European Journal of Clinical Investigation. 2018;48(2) (no pagination):e12872.

75. Marioni RE, Harris SE, Shah S, McRae AF, von Zglinicki T, Martin-Ruiz C, Wray NR, Visscher PM, Deary IJ. The epigenetic clock and telomere length are independently associated with chronological age and mortality. Int J Epidemiol. 2016;45(2):424-32

76. Kim S, Myers L, Wyckoff J, Cherry KE, Jazwinski SM. The frailty index outperforms DNA methylation age and its derivatives as an indicator of biological age. Geroscience. 2017;39(1):83-92.

77. Wolf EJ, Logue MW, Stoop TB, Schichman SA, Stone A, Sadeh N, Hayes JP, Miller MW. Accelerated DNA methylation age: associations with posttraumatic stress disorder and mortality. Psychosom Med. 2018;80(1):42-8.

78. Perna L, Zhang Y, Mons U, Holleczek B, Saum KU, Brenner H. Epigenetic age acceleration predicts cancer, cardiovascular, and all-cause mortality in a German case cohort. Clin Epigenetics. 2016;8:64.

79. Riley RD, Higgins JPT, Deeks JJ. Interpretation of random effects metaanalyses. BMJ (Clinical research ed). 2011;342:d549.

80. Horvath S, Raj K. DNA methylation-based biomarkers and the epigenetic clock theory of ageing. Nat Rev Genet. 2018;19(6):371-84.

81. Rosero-Bixby L, Dow WH, Rehkopf DH. The Nicoya region of Costa Rica: a high longevity island for elderly males. Vienna yearbook of population research. 2013;11:109-36.

82. Garinis GA, van der Horst GT, Vijg J, Hoeijmakers JH. DNA damage and ageing: new-age ideas for an age-old problem. Nat Cell Biol. 2008;10(11):1241-7.

83. Huang WY, Hsu SD, Huang HY, Sun YM, Chou CH, Weng SL, Huang HD. MethHC: a database of DNA methylation and gene expression in human cancer. Nucleic Acids Res. 2015;43(D1):D856-D61. 
84. Matosin N, Cruceanu C, Binder EB. Preclinical and Clinical Evidence of DNA Methylation Changes in Response to Trauma and Chronic Stress. Chronic stress (Thousand Oaks, Calif). 2017;1.

85. Park SL, Patel YM, Loo LWM, Mullen DJ, Offringa IA, Maunakea A, Stram DO, Siegmund K, Murphy SE, Tiirikainen M, et al. Association of internal smoking dose with blood DNA methylation in three racial/ethnic populations. Clin Epigenetics. 2018;10(1):110.

86. Wagner KH, Cameron-Smith D, Wessner B, Franzke B. Biomarkers of Aging: From Function to Molecular Biology. Nutrients. 2016;8(6):E338.

87. Xia X, Chen W, McDermott J, Han JJ. Molecular and phenotypic biomarkers of aging. F1000Research. 2017;6:860

Ready to submit your research? Choose BMC and benefit from:

- fast, convenient online submission

- thorough peer review by experienced researchers in your field

- rapid publication on acceptance

- support for research data, including large and complex data types

- gold Open Access which fosters wider collaboration and increased citations

- maximum visibility for your research: over $100 \mathrm{M}$ website views per year

At BMC, research is always in progress.

Learn more biomedcentral.com/submissions 